\title{
Impact FEA Simulation and Analysis of Custom-made Cranial Implants
}

\author{
MIHAELA-ELENA ULMEANU ${ }^{1}$, CRISTIAN-VASILE DOICIN ${ }^{1}$, ILEANA MATES ${ }^{2 *}$, \\ ROMAN MURZAC ${ }^{1}$, DRAGOS DAVITOIU ${ }^{3}$ \\ ${ }^{1}$ University Politehnica of Bucharest, Faculty of Industrial Engineering and Robotics, Department of Manufacturing, \\ 313 Splaiul Independenței, 060032, Bucharest, Romania \\ ${ }^{2}$ University Politehnica of Bucharest, Faculty of Material Science and Engineering, Department of Environmental \\ Engineering, 313 Splaiul Independenței, 060032, Bucharest, Romania \\ ${ }^{3}$ University of Medicine and Pharmacy Carol Davila Bucharest, Faculty of Medicine, Department of General Surgery, \\ 37 Dionisie Lupu Str., 020021, Bucharest, Romania
}

\begin{abstract}
Cranioplasty is a surgical procedure used to repair cranial defects left behind after injury or previous surgeries. Postoperative results of cranioplasty have been drastically improved with the usage of custom made cranial implants, which can replicate the missing bone almost identical in shape. Materials used for these custom implants vary depending on the used technology. Additive manufactured implants are generally made with metal alloys powders. The present research conducts a Finite Element Analysis study in regard to modification of intracranial pressure conditions, in normal range between $7 \mathrm{~mm} \mathrm{Hg}$ to $15 \mathrm{~mm} \mathrm{Hg}$, in four impact stress scenarios of fixed custom cranial implants. Two new cranial implant concepts are proposed by the authors, one with a sliding system and one with osteointegrating structures. Stress scenarios aim at evaluating implant behaviour in critical conditions such as a person falling from a certain height or an object being dropped, generating an impact point on the surface of the implant. Deformations, displacements and equivalent strain were analysed. Scenarios 1, 2 and 4 provided results within the limit values for Von Misses stress and equivalent strain for both cranial implant concepts and both considered materials, Ta and Ti6Al4V. ICP values are in limits for all four stress scenarios, due to the small values of the implants' deformations.
\end{abstract}

Keywords: custom cranial implant, metal additive manufacturing, impact Finite Element Analysis

\section{Introduction}

A wide variety of surgical techniques, materials, and medical devices are used to perform cranioplasty procedures. Currently, the most used medical devices for cranioplasty are: plaques, nets, distractions, autografts and allografts [1]. The most used fastening method is by screw driving minibolts. The fastening is usually made in relation to the contour of the undamaged skull.

With the evolution of additive manufacturing systems and technologies, medical devices used in the reconstruction of bone defects have developed in terms of types of materials used and constructive forms, now being as similar as possible to the anatomy of the patient. Due to the advantages, personalized implant manufacturing is currently considered to bring the most benefits in terms of compliance with the patients' needs [2]. Also, a personalized implant significantly reduces the duration of surgery and, implicitly, postoperative complications. However, a cranial implant which is manufactured in a unique part production manner, has high costs compared to standardized devices on the market [3, 4].

Complications of cranioplasty are classified into three main categories, as follows: 1. septic complications - osteomyelitis, meningoencephalitis, cerebral abscess; 2. neurological complications circumscribed cerebral contusion, intracranial hematoma, duro-cerebral dilaceration, cranial nerve lesions, epilepsy; 3. fluid complications - cerebrospinal fluid fistula [5-7]. Septic complications usually

*email: ileana.mates@yahoo.ro 
occur when the surgical site is not properly cleaned. Often, splinters that occur when bolt implants are attached further damage surrounding tissues, leading to septic or fluid complications. In rare cases, mechanical fixation of implants can lead to neurological complications.

Thus, a new need has been identified, regarding the development of a cranial implant that ensures patient personalizati

on at a low cost and which no longer requires a fastening system by additional drilling of the skull. Also, better osteointegration is required for customized cranial implants.

In order to satisfy this identified need, the authors propose two customizable cranial implants, without having to process specific anatomical data and manufacture a unique prosthesis for a patient. Both cranial implants are constructed with inter-movable layers which can accommodate different sizes and shapes of a cranial traumas' aperture. One of the concepts also allows fixation without the need to drill into the patients' skull, reducing related complications.

Although both proposed implants provide theoretical multi-functionality and advantages, they also need to be safe for the patient in everyday use. One of the most important parameters that needs to be taken into account during the analysis of the safety in usage of a cranial implant is intracranial pressure (ICP). Any changes outside the normal range can be a potential danger to the patients' health [8].

This research conducts a FEA study in regard to modification of ICP conditions, in normal range between $7 \mathrm{~mm} \mathrm{Hg}$ to $15 \mathrm{~mm} \mathrm{Hg}[8,9]$, in four impact stress scenarios of fixed custom cranial implants. The most common metal powders for additive manufacturing used in medical applications are considered for this study, namely: tantalum and Ti6Al4V titanium alloy. Stress scenarios follow implant behavior in critical conditions such as a person falling from a certain height or an object being dropped, generating an impact point on the surface of the implant. Deformations, displacements and equivalent strain were analysed to assess the changes of ICP in different stress scenarios.

\section{Materials and methods}

The paper aims to evaluate the compliancy with impact human safety limit values [8, 9] by deploying simulation and analysis of two custom cranial implants obtained with metal additive manufacturing technologies. In everyday life the beneficiary of a cranial implant might sustain different types of injuries related to ordinary activities and tasks. The behavior of the custom cranial implants under critical circumstances needs to be thoroughly evaluated in order to prevent safety hazards caused by the main following implant related complications: implant displacement, migration, deformation and fragment rupture. All of which could affect the patient irremediably.

Authors designed the custom cranial implants targeting additive manufacturing technologies as the main option for fabrication. Thus, special and unique features were incorporated into the design of the implants, leading to several advantages over existing similar products. Implant impact behavior under mechanical stress was evaluated by defining four possible scenarios, which are described in the following sections of the paper. Injuries inflicted either by a falling object or by falling of the patient were considered. The impact zone was established to be directly onto the surface of the mounted custom cranial implant.

\section{Concepts of custom cranial implants}

Two custom cranial implants concepts previously designed by the authors are proposed for the FEA investigation $[10,11]$.

The first cranial implant concept is a custom endoprosthesis with sliding system (Figure 1). It was designed by the authors to help repair traumatic defects of the skull through the surgical procedure of cranioplasty.

One of the main advantages of this concept is that the sliding system allows adaptation of the endoprosthesis to a variety of aperture dimensions of the cranial trauma. This facilitates large scale production of the cranial implant, maintaining personalization according to a specific patients' anatomy. The designed fastening system does not require drilling of the patient's skull, diminishing 
post-traumatic complications, promoting faster recovery of the patient and reducing the duration of the fixation, implicitly the duration of the intra-operator surgical procedure.

Mechanical stress evaluation of the custom cranial implant involves a thorough knowledge regarding the implants' subassemblies and components.

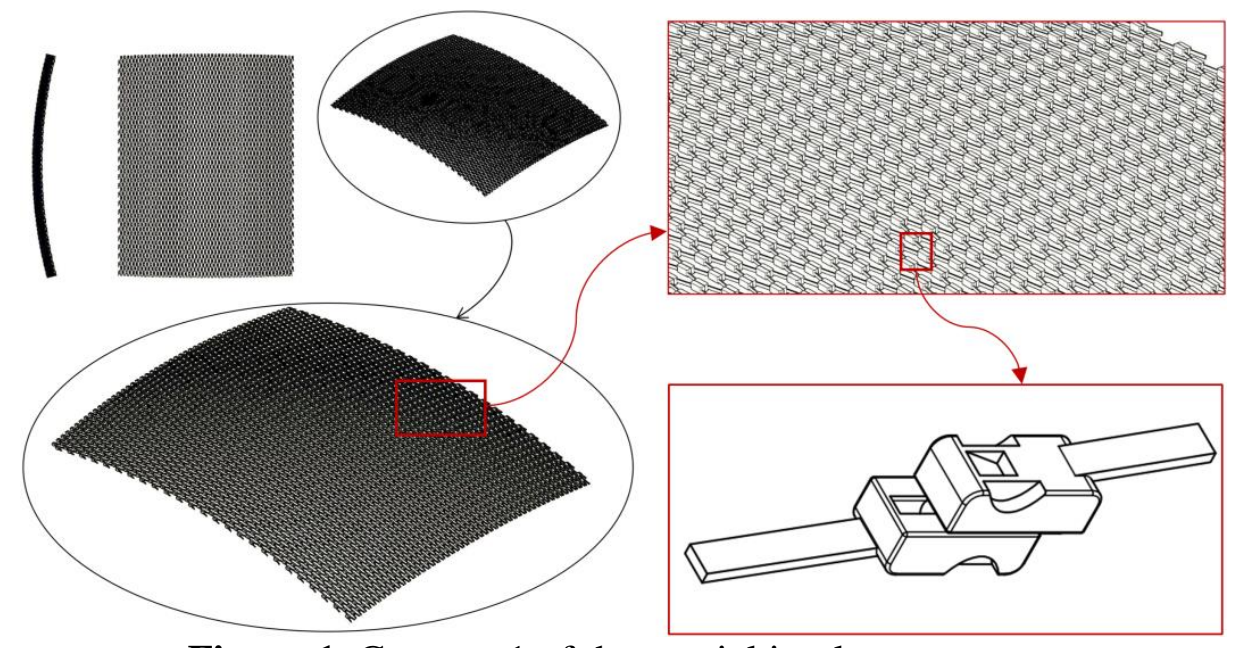

Figure 1. Concept 1 of the cranial implant - custom endoprosthesis with sliding system

The cranial implant with sliding system consists of three main subassemblies: a top sliding layer, a lower sliding layer and a fastening system. Sliding is performed and propagated along the implants' surface due to the unique design of the base unit cell (Figure 1). Positioning is done in relation to the cranial trauma apertures' size and shape and is fitted into its' final position with an action key (Figure 2). In a similar way the upper sliding layer is positioned, and the permanent fastening is done by connecting the lower and upper layers with fixing pins and gripping brackets, without damaging the skull and other anatomical parts all throughout the procedure (Figure 2).
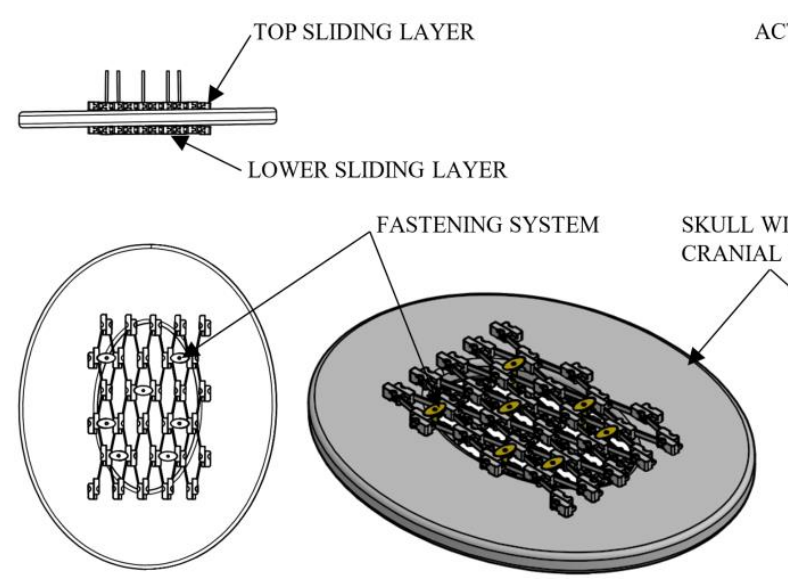

a)

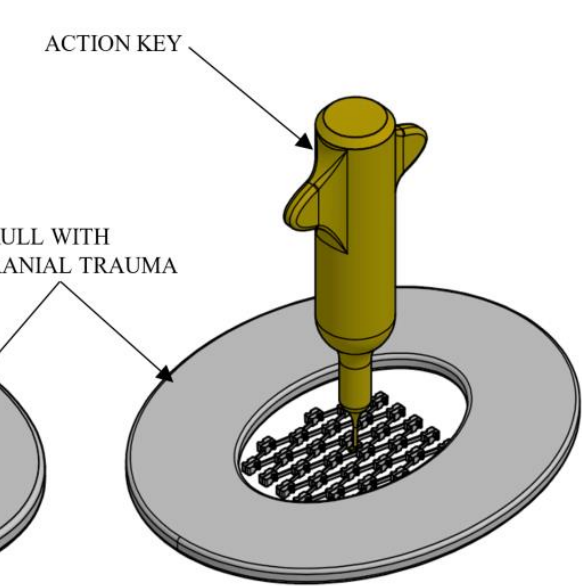

b)

Figure 2. Positioning and assembly of the custom endoprosthesis with sliding system: a)assembled and fastened cranial implant; b) lower sliding layer before fitted into final position with action key

The second cranial implant concept is comprised of custom osteointegration structures and functional coatings (Figure 3). This concept was designed to be used especially for cranioplasty and reconfiguration of major cranial defects accidents, congenital abnormalities, surgical interventions due to tumor extractions or other cranial disorders, promoting osteointegration through functional coatings based on selenium and/ or hydroxyapatite nanoparticles. The chemical composition of the coatings is 
not the subject of this paper and will not be further detailed.

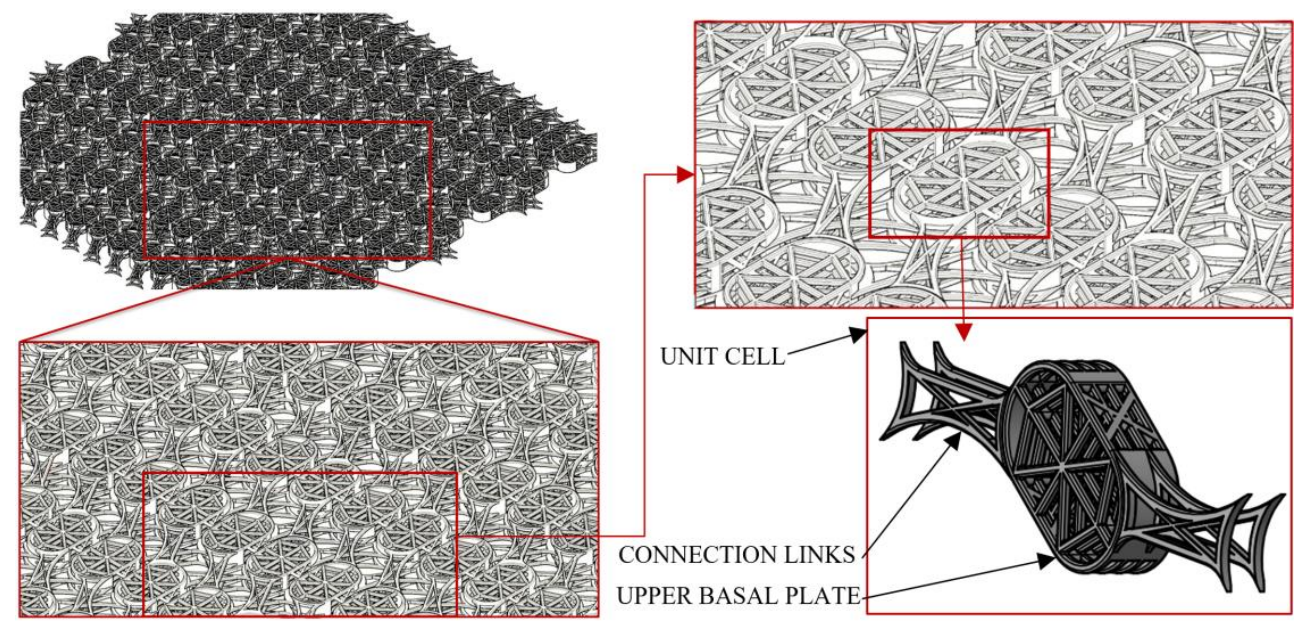

Figure 3. Concept 2 of the cranial implant - custom cranial implant with osteointegration structures and functional coatings

The structure of the cranial implant with osteointegration structures consists of two layers, one fixed and the other movable, interconnected so that the translations in the Ox and Oy directions can be achieved, while retaining the one fixed layer (Figure 3). The unit cells of the two layers are arranged in two directions whose intersection at any point forms a variable angle. Each layer has a differently designed unit cell in regard to the connection links position. All implant constructive elements have a porous microstructure that favors the absorption of substances which promote osteointegration. Considering the principles of mimetics, the unit cells are composed of four basal plates with a geometric structure of the spider web with and features characterized by sharp angles (Figure 3 ). These favour the capillary process for retention of various chemical substances. An important advantage is the flexibility of the cranial implant, provided by the interconnected unit cells, which allows adaptation to the patient's anatomy, while preserving mechanical strength characteristics.

\section{FEA simulation hypothesis}

In order to conduct a FEA study on modification of ICP conditions within normal range (between 7 $\mathrm{mm} \mathrm{Hg}$ to $15 \mathrm{~mm} \mathrm{Hg}[8,9]$ ), four impact stress scenarios are defined based on two main work hypothesis: 1) an object being dropped, 2) a patient falling from a certain height. Both hypotheses assume that the impact is generated on the surface of the implant, which is mounted onto the patient after a successful cranioplasty.

The first hypothesis assumes a patient weighing 78 kilograms is standing in a kneeling working position and is hit on the head by a $2.7 \mathrm{Kg}$ falling brick (Figure 4a). The brick was considered to be $15.24 \mathrm{~cm}$ by $10.16 \mathrm{~cm}$ by $5.08 \mathrm{~cm}$ and falling from a height of $3.35 \mathrm{~m}$, striking the head of the patient with the $15.24 \mathrm{~cm}$ edge at a right angle. A variation of this hypothesis was proposed, resulting in three scenarios: 1a) brick strikes flat, 1b) brick strikes on edge, 1c) brick strikes on corner.

The second hypothesis involves a patient weighing 78 kilograms, which falls 3.35 meters to land on his head on a surface that deflects 0.3 meters upon impact (Figure 4b). 

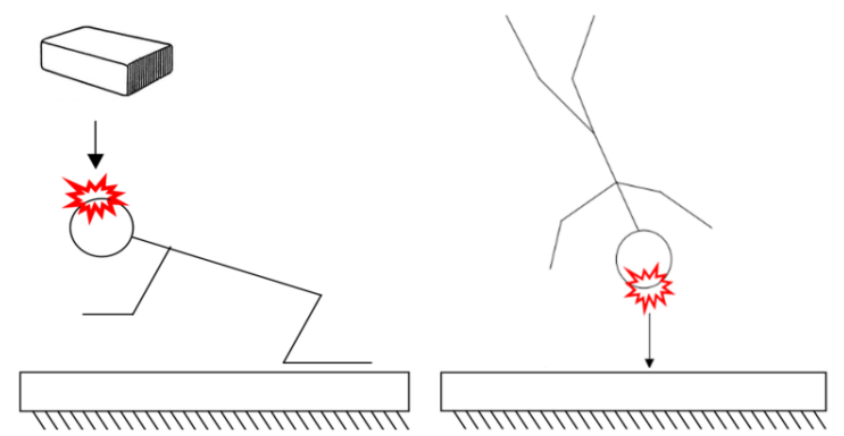

Figure 4. Visual representation of the injury scenarios: a) Hypothesis 1: Object falling on head; b) Hypothesis 2: Patient falling on head.

The values used to calculate the body mass of the person falling from a $3.35 \mathrm{~m}$ distance on his head are correspondent to the body typo dimensions of the average human male [12].

In order to perform the FEA simulations for all four stress scenarios described above, the main computational input parameters need to be calculated. The computed values of the simulation parameters for all four scenarios are summarised in Tables 1 and 2 presented below. They are calculated according the formulas given by Brauer R.L. in his 2006 second edition of the book entitled "Safety and Health for Engineers" [13].

Table 1. Computational values of simulation parameters for Scenario 1: Object falling on head

\begin{tabular}{|c|c|c|c|c|c|c|c|c|c|}
\hline $\begin{array}{c}\text { Distance } \\
\text { of Fall }\end{array}$ & $\begin{array}{c}\text { Velocity } \\
\text { on } \\
\text { Impact }\end{array}$ & $\begin{array}{c}\text { Deceleration } \\
\text { Distance }\end{array}$ & $\begin{array}{c}\text { Rate of } \\
\text { Deceleration }\end{array}$ & Weight & $\begin{array}{c}\text { Force } \\
\text { of } \\
\text { Impact }\end{array}$ & Time & $\begin{array}{c}\text { Area of } \\
\text { Impact }\end{array}$ & $\begin{array}{c}\text { Pressure } \\
\text { of } \\
\text { Impact }\end{array}$ & Scenario No. \\
\hline$[\mathbf{m}]$ & {$[\mathbf{m} / \mathbf{s}]$} & {$[\mathbf{m}]$} & {$\left[\mathbf{m} / \mathbf{s}^{2}\right]$} & {$[\mathbf{k g}]$} & {$[\mathbf{N}]$} & {$[\mathbf{s}]$} & {$\left[\mathbf{m m}^{2}\right]$} & {$[\mathbf{M P a}]$} & \\
\hline 3.35 & 8.11 & 0.0064 & 5.18 & 2.72 & 14.1 & 0.83 & 15483.8 & 0.001 & $1 \mathrm{a}:$ Strikes flat \\
\hline 3.35 & 8.11 & 0.0064 & 5.18 & 2.72 & 14.1 & 0.83 & 967.74 & 0.015 & $1 \mathrm{~b}:$ Strikes on edge \\
\hline 3.35 & 8.11 & 0.0064 & 5.18 & 2.72 & 14.1 & 0.83 & 402.2 & 0.35 & $1 \mathrm{c}:$ Strikes on corner \\
\hline
\end{tabular}

Table 2. Computational values of simulation parameters for Scenario 2: Landing on head

\begin{tabular}{|c|c|c|c|c|c|c|c|c|c|}
\hline $\begin{array}{c}\text { Distance } \\
\text { of Fall }\end{array}$ & $\begin{array}{c}\text { Velocity } \\
\text { on } \\
\text { Impact }\end{array}$ & $\begin{array}{c}\text { Deceleration } \\
\text { Distance }\end{array}$ & $\begin{array}{c}\text { Rate of } \\
\text { Deceleration }\end{array}$ & Weight & $\begin{array}{c}\text { Force } \\
\text { of } \\
\text { Impact }\end{array}$ & Time & $\begin{array}{c}\text { Area of } \\
\text { Impact }\end{array}$ & $\begin{array}{c}\text { Pressure } \\
\text { of } \\
\text { Impact }\end{array}$ & Scenario No. \\
\hline$[\mathbf{m}]$ & {$[\mathbf{m} / \mathbf{s}]$} & {$[\mathbf{m}]$} & {$\left[\mathbf{m} / \mathbf{s}^{\mathbf{2}}\right]$} & {$[\mathbf{k g}]$} & {$[\mathbf{N}]$} & {$[\mathbf{s}]$} & {$\left[\mathbf{m m}^{2}\right]$} & {$[\mathbf{M P a}]$} & \\
\hline 3.35 & 8.11 & 0.3 & 107.9 & 78 & 8.42 & 0.83 & 80.65 & 0.104 & 2: Landing on head \\
\hline
\end{tabular}

Two main materials were considered for the manufacturing of the cranial implants, as follows: tantalum (Ta) and titanium alloy (Ti6Al4V). Materials were selected due to their suitability for powder metal additive manufacturing technologies like Electron Beam Melting (EBM) and Laser Powder Bed (L-PBF). Ti6Al4V is the most widely used titanium alloy. It features good machinability and excellent mechanical properties. Ti6Al4V is extensively used in numerous applications in the medical industry, due to its excellent biocompatibility, especially when direct contact with tissue or bone is required [14].

Although still in its early adoption in additive manufacturing applications [15], tantalum was considered for analysis especially due to its uniquely beneficial properties with respect to some of the other refractory metals $[13,16]$. Tantalum has a high weight to strength ratio, a high melting point and excellent biocompatibility and osteointegration attributes [13, 16]. Highly resistant to heat and chemically inert, the material can be difficult to work with in metal 3D printing processes, but also make it valuable to high stress applications [17].

To keep track of each simulation scenario, as FEA is undertaken for two concepts, two materials and four stress scenarios, codes are assigned to each one according to Table 3. 
Table 3. Codification of scenario simulations for the two concepts of the custom cranial implants

\begin{tabular}{|c|c|c|c|}
\hline Scenario simulation code & Cranial implant concept no. & Material & Scenario no. \\
\hline 1.1.1 & 1: with sliding system & Ti6Al4V & 1a: Strikes flat \\
\hline 1.1 .2 & 1: with sliding system & Ti6Al4V & 1b: Strikes on edge \\
\hline 1.1 .3 & 1: with sliding system & Ti6Al4V & 1c: Strikes on corner \\
\hline 1.1 .4 & 1: with sliding system & Ti6Al4V & 2: Landing on head \\
\hline 1.2 .1 & 1: with sliding system & $\mathrm{Ta}$ & 1a: Strikes flat \\
\hline 1.2 .2 & 1: with sliding system & $\mathrm{Ta}$ & 1b: Strikes on edge \\
\hline 1.2 .3 & 1: with sliding system & $\mathrm{Ta}$ & 1c: Strikes on corner \\
\hline 1.2 .4 & 1: with sliding system & $\mathrm{Ta}$ & 2: Landing on head \\
\hline 2.1 .1 & 2: with osteointegrating structures & Ti6Al4V & 1a: Strikes flat \\
\hline 2.1.2 & 2: with osteointegrating structures & Ti6Al4V & 1b: Strikes on edge \\
\hline 2.1 .3 & 2: with osteointegrating structures & Ti6Al4V & 1c: Strikes on corner \\
\hline 2.1 .4 & 2: with osteointegrating structures & Ti6Al4V & 2: Landing on head \\
\hline 2.2 .1 & 2: with osteointegrating structures & $\mathrm{Ta}$ & 1a: Strikes flat \\
\hline 2.2 .2 & 2: with osteointegrating structures & $\mathrm{Ta}$ & 1b: Strikes on edge \\
\hline 2.2 .3 & 2: with osteointegrating structures & $\mathrm{Ta}$ & 1c: Strikes on corner \\
\hline 2.2 .4 & 2: with osteointegrating structures & $\mathrm{Ta}$ & 2: Landing on head \\
\hline
\end{tabular}

All simulation scenarios were run using the material properties given in Table 4 below. When running the FEA study the material properties, for both Tantalum and Ti6Al4V, are assumed to be linearly elastic, homogeneous and isotropic.

Table 4. Mechanical characteristics of Tantalum and Ti6Al4V used for scenarios simulation

\begin{tabular}{|c|c|c|}
\hline Property & Tantalum & Ti6Al4V \\
\hline Density [g/cm3] & 16.65 & 4.43 \\
\hline Ultimate Tensile Strength [MPa] & 900 & 950 \\
\hline Yield Strength [MPa] & 825 & 880 \\
\hline Poisson's ratio & 0.35 & 0.34 \\
\hline Modulus of Elasticity [GPa] & 186 & 113.8 \\
\hline Shear Modulus [GPa] & 68.89 & 42.46 \\
\hline
\end{tabular}

\section{Results and discussions}

Simulation results were analyzed considering the following stages: Mesh compilation; Study simulation with integrated solver; First evaluation of simulation results; Optimize chart characteristics; Generation of the simulation reports; Interpretation of results; Simulation conclusions regarding the cranial implants mechanical behavior. All plots contain as a superimposed model the initial undeformed shape of the implant, marked with a transparent color.

Loads and fixtures were defined for all four stress scenarios according to the computed values presented in Table 1 and Table 2. In accordance to recommendations given by Radostina [18], several types of FEA studies were defined for each of the four proposed scenarios, as follows: Von Misses stress; Resultant Displacement; Displacement on X, Y, Z directions; Equivalent Strain.

Graphical representations of the FEA results for Concept no 1 of the cranial implant with a sliding system, manufactured from Ti6Al4V, are presented in Table 5 for all four stress scenarios. Graphical representations of the FEA results in stress scenario 2, for Concept no 2 of the cranial implant with osteointegration structures, manufactured from Ta, are presented in Table 6. 
Table 5. FEA graphical representation results for Concept 1 of the cranial implant - Ti6Al4V

\begin{tabular}{|c|c|c|c|}
\hline $\begin{array}{l}\text { Scenario } \\
\text { No. }\end{array}$ & VON MISSES STRESS & RESULTANT DISPLACEMENT & EQUIVALENT STRAIN \\
\hline 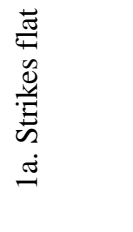 & 1 & $\zeta$ & Lin \\
\hline 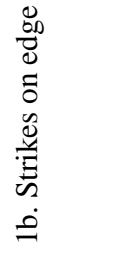 & $\because$ & & $\because$ \\
\hline 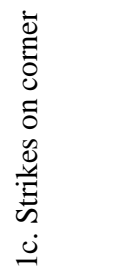 & $\because$ & 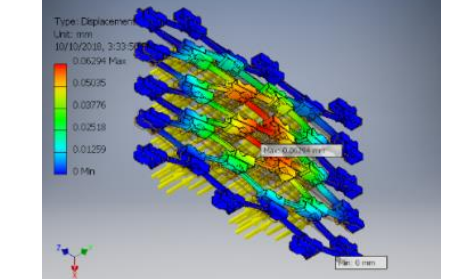 & 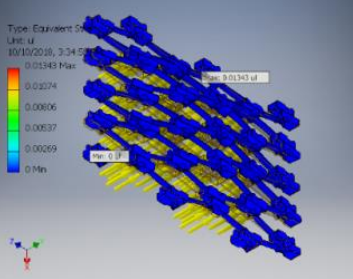 \\
\hline 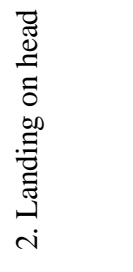 & जी & 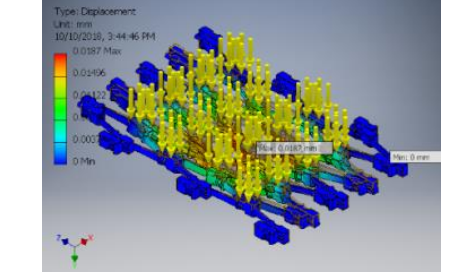 & \\
\hline
\end{tabular}

Table 6. FEA graphical representation results for Concept 2 of the cranial implant $-T a$

\begin{tabular}{|c|c|c|c|}
\hline $\begin{array}{c}\text { Scenario } \\
\text { No. }\end{array}$ & VON MISSES STRESS & RESULTANT DISPLACEMENT & EQUIVALENT STRAIN \\
\hline 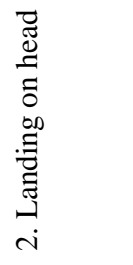 & 1. & 7 & (2) \\
\hline
\end{tabular}

For a better understanding, value comparison and result interpretation, all FEA simulation results are compiled in Table 7. 
Table 7. FEA simulation results for two custom cranial implants manufactured from Tantalum and Ti6Al4V, in four stress scenarios

\begin{tabular}{|c|c|c|c|c|c|c|c|c|c|c|c|c|}
\hline \multirow[t]{2}{*}{$\begin{array}{l}\text { FEA } \\
\text { Code }\end{array}$} & \multicolumn{2}{|c|}{$\begin{array}{c}\text { Von Misses Stress } \\
\text { [MPa] }\end{array}$} & \multicolumn{2}{|c|}{$\begin{array}{c}\text { Resultant } \\
\text { Displacement } \\
{[\mathrm{mm}]}\end{array}$} & \multicolumn{2}{|c|}{$X$ Displacement $[\mathrm{mm}]$} & \multicolumn{2}{|c|}{$\begin{array}{l}\text { Y Displacement } \\
{[\mathrm{mm}]}\end{array}$} & \multicolumn{2}{|c|}{$\begin{array}{c}\text { Z Displacement } \\
{[\mathrm{mm}]}\end{array}$} & \multicolumn{2}{|c|}{ Equivalent Strain } \\
\hline & Min & Max & Min & Max & Min & $\operatorname{Max}$ & Min & Max & Min & $\operatorname{Max}$ & Min & $\operatorname{Max}$ \\
\hline 1.1 .1 & $3.8 \cdot 10^{-6}$ & & 0 & 1.19 & -2.68 . & & & & & $1.45 \cdot 10^{-5}$ & $3.09 \cdot 10^{-11}$ & \\
\hline 1.1 .2 & & & - & & & & $-2.28 \cdot 10^{-4}$ & $2.69 \cdot 10^{-3}$ & $-2.00 \cdot 10^{-4}$ & $2.18 \cdot 10^{-4}$ & $4.63 \cdot 10^{-10}$ & \\
\hline 1.1 .3 & & 1. & 0 & & & $9.96 \cdot 10^{-3}$ & $-5.32 \cdot 10^{-3}$ & $6.29 \cdot 10^{-2}$ & $-4.67 \cdot 10^{-3}$ & $5.10 \cdot 10^{-3}$ & $1.08 \cdot 10^{-8}$ & $1.34 \cdot 10^{-2}$ \\
\hline 1.1 .4 & $8 \cdot 10^{-4}$ & & 0 & $1.87 \cdot 10^{-2}$ & $-2.79 \cdot 10^{-3}$ & $2.96 \cdot 10^{-3}$ & $-1.58 \cdot 10^{-3}$ & $1.86 \cdot 10^{-2}$ & $-1.39 \cdot 10^{-3}$ & $3.99 \cdot 10^{-3}$ & $3.21 \cdot 10^{-9}$ & 3.5 \\
\hline 1.2 .1 & & & -2 & & $4 \cdot 10^{-5}$ & $1.74 \cdot 10^{-5}$ & $-9.21 \cdot 10^{-6}$ & $1.10 \cdot 10^{-4}$ & $-8.18 \cdot 10^{-6}$ & $8.92 \cdot 10^{-6}$ & $2.14 \cdot 10^{-11}$ & \\
\hline 1.2 .2 & & 6 & 0 & & & $2.61 \cdot 10^{-4}$ & $-1.38 \cdot 10^{-4}$ & $1.65 \cdot 10^{-3}$ & & $1.33 \cdot 10^{-4}$ & $3.21 \cdot 10^{-10}$ & $3.50 \cdot 10^{-4}$ \\
\hline 1.2 .3 & & & 0 & & & $6.10 \cdot 10^{-3}$ & & & & & $0^{-9}$ & \\
\hline 1.2 .4 & & $46^{\circ}$ & 0 & $1.14 \cdot 10^{-2}$ & $-1.71 \cdot 10^{-3}$ & $1.81 \cdot 10^{-3}$ & $-9.58 \cdot 10^{-4}$ & $1.14 \cdot 10^{-2}$ & -8.5 & $0^{-4}$ & $22 \cdot 10^{-9}$ & 2. \\
\hline 2.1 .1 & $7.09 \cdot 10^{-8}$ & 372684 & 0 & $5.95 \cdot 10^{-4}$ & $-2.60 \cdot 10^{-5}$ & $2.60 \cdot 10^{-5}$ & $-2.30 \cdot 10^{-5}$ & $2.39 \cdot 10^{-5}$ & $-5.95 \cdot 10^{-4}$ & $1.43 \cdot 10^{-5}$ & $7.14 \cdot 10^{-13}$ & 3.02 \\
\hline 2.1 .2 & & & 0 & & & & $\cdot 10^{-4}$ & & & & $1.09 \cdot 10^{-11}$ & \\
\hline 2.1 .3 & $0^{-5}$ & 49 & 0 & 88 & $-9.10 \cdot 10^{-3}$ & $9.11 \cdot 10^{-3}$ & $-8.05 \cdot 10^{-3}$ & $8.39 \cdot 10^{-3}$ & -0 & $5.01 \cdot 10^{-3}$ & $2.82 \cdot 10^{-10}$ & $1.06 \cdot 10^{-2}$ \\
\hline 2.1.4 & $6.71 \cdot 10^{-6}$ & 38723 & 0 & $6.19 \cdot 10^{-2}$ & $-2.70 \cdot 10^{-3}$ & $2.70 \cdot 10^{-3}$ & $-2.39 \cdot 10^{-3}$ & $2.49 \cdot 10^{-3}$ & $-6.19 \cdot 10^{-2}$ & $1.49 \cdot 10^{-3}$ & $5.35 \cdot 10^{-11}$ & $3.15 \cdot 10^{-3}$ \\
\hline 2.2 .1 & $3 \cdot 10^{-8}$ & & 0 & $3.64 \cdot 10^{-4}$ & $.58 \cdot 10^{-5}$ & $1.59 \cdot 10^{-5}$ & $-1.40 \cdot 10^{-5}$ & $1.46 \cdot 10^{-5}$ & $-3.64 \cdot 10^{-4}$ & $8.76 \cdot 10^{-6}$ & $2.79 \cdot 10^{-13}$ & 1.85 \\
\hline 2.2 .2 & $1.18 \cdot 10^{-6}$ & & 0 & $5.46 \cdot 10^{-3}$ & $-2.38 \cdot 10^{-4}$ & $2.38 \cdot 10^{-4}$ & $-2.11 \cdot 10^{-4}$ & $2.20 \cdot 10^{-4}$ & $-5.46 \cdot 10^{-3}$ & $1.31 \cdot 10^{-4}$ & $5.78 \cdot 10^{-12}$ & $2.78 \cdot 10^{-4}$ \\
\hline 2.2 .3 & $1.97 \cdot 10^{-5}$ & 130 & 0 & 0.127543 & $-5.56 \cdot 10^{-3}$ & $5.57 \cdot 10^{-3}$ & $-4.92 \cdot 10^{-3}$ & $5.13 \cdot 10^{-3}$ & -0.1275 & $3.06 \cdot 10^{-3}$ & $9.97 \cdot 10^{-11}$ & $6.50 \cdot 10^{-3}$ \\
\hline 2.2 .4 & $8.14 \cdot 10^{-6}$ & 387.219 & 0 & $3.78 \cdot 10^{-2}$ & $-1.65 \cdot 10^{-3}$ & $1.65 \cdot 10^{-3}$ & $-1.46 \cdot 10^{-3}$ & $1.52 \cdot 10^{-3}$ & $-3.78 \cdot 10^{-2}$ & $9.12 \cdot 10^{-4}$ & $3.98 \cdot 10^{-11}$ & $1.93 \cdot 10^{-3}$ \\
\hline
\end{tabular}

The FEA results presented in Table 7 show that tantalum had better overall performances on all investigated parameters, for both cranial implant concepts.

Concept no. 2 has superior stability regarding the $\mathrm{X}, \mathrm{Y}$ and $\mathrm{Z}$ displacements in all four scenarios and in both material options.

The von Misses Stress distribution obtained by FEA states weather the assembly will withstand the design load. Comparing the obtained values with the yield strength of the material used to manufacture the cranial implant, it is clear that the assembly did not fail under the designed load distribution in scenarios 1, 2 and 4. The Von Misses stress simulation results for scenarios 1,2 and 4 are situated below the yield point value of $880 \mathrm{MPa}$ for Ti6Al4V, respectively $825 \mathrm{MPa}$ for Ta. The situation is similar for both proposed cranial implant concepts.

Resultant displacement study is used to determine how the CAD model moves under the defined loads. The Resultant Displacement generates the magnitude of the resultant (compounded from the X, $\mathrm{Y}$ and $\mathrm{Z}$ directions) reaction force. As it can be observed in Table 7, all resultant displacement values are situated under the standard $\pm 3 \mathrm{~mm}$ deflection limit. In order to provide additional safety measures, further displacement studies were undertaken for all four stress scenarios to evaluate the magnitude of the reaction forces on the $\mathrm{X}, \mathrm{Y}$ and $\mathrm{Z}$ individual directions. Simulation results they clearly show that the standard deflection limit is not exceeded, as compared with the result obtained by Personn et. all [20].

The equivalent strain was used to measure the geometric response and the change in shape (deformation) due to applied forces for all four defined load scenarios. The equivalent strain is computed as the ratio between the maximum triaxial stress and the Elastic Modulus. In order for the cranial implant to withstand the design load, equivalent strain values (Table 7) should be less than the coefficient given by the ratio between the Yield Strength and the Elastic Modulus. As the Elastic Modulus for Ti6Al4V has a value of $113.8 \mathrm{GPa}$, all corresponding simulation results values will be compared with a $7.73 .10^{-3}$ coefficient. The Elastic Modulus for Ta is $186 \mathrm{GPa}$, consequently all corresponding simulation results values will be compared with a $4.43 .10^{-3}$ coefficient. Analyzing the values from Table 7 it can be observed that equivalent strain simulation results for scenarios 1,2 and 4 are situated below the limit coefficients, for both implants manufactured in Ta and Ti6Al4V. All scenario 3 results are above the limit values of the coefficients and do not comply with the equivalent strain limits of the materials. Considering an average value of the skull, of about $1400 \mathrm{cc}$ [19], the upper limit of the normal ICP, of about $15 \mathrm{~mm} \mathrm{Hg}$, and the fact that a swelling inside the skull causes 
an almost equal increase in pressure across the entire cranial box, we may calculate the variation of the pressure when changing the shape of the cranial implant by deforming it to the inside of the skull, maintaining constant temperature, and considering that the pressure is instantly and evenly transmitted across the entire cranial box. In such a case, a deformation of the cranial implant to the inside of the skull, so that the inner volume is reduced by $5 \mathrm{cc}$, which corresponds to major trauma, produces an increase in ICP pressure of about $0.05 \mathrm{mmHg}$, negligible. The simulations show that the real deformation (Table 7 and the results from [20]) is more than 103 times smaller, which means that the implant is safe to use, and the standard situations in which the patient can be found do not in any way imply the increase of ICP due to implant deformation. All values marked in a red color from Table 7 are above the limits set for each specific stress scenario, meaning that the implant did not withstand the applied stresses, and need redesign according to the critical points registered. Further research will address these scenarios.

\section{Conclusions}

Four simulation scenarios were developed for the behavior analysis of two new cranial implant concepts. The first three simulation scenarios consist of an object being dropped: 1a) object strikes flat, 1b) object strikes on edge, 1c) object strikes on corner. The fourth simulation scenario assumes that a patient is falling from a certain height and hits his head at the location of the implant.

For the deployment of the proposed study, the most common metal powders for additive manufacturing used in medical applications were considered, namely: tantalum and Ti6Al4V titanium alloy.

Tantalum had better overall performances on all investigated parameters, for both cranial implant concepts. Concept no. 2 has superior stability regarding the $\mathrm{X}, \mathrm{Y}$ and $\mathrm{Z}$ displacements in all four scenarios and in both material options.

The third scenario had values exceeding the material-imposed limits for the Von Misses Stress and the Equivalent Strain.

The simulations demonstrate that the deformation values are low enough not to cause the increase of the ICP in the standard cases of accidents caused by blows in the implant area.

Acknowledgments: The work was partially developed under the project "Work-based learning systems through entrepreneurial scholarships for doctoral and post-doctoral students (SIMBA) MySMIS 124705” within Priority Axis 6 - Education and skills - POCU 2014-2020

\section{References}

1. AYDIN, S., KUCUKYURUK, B., ABUZAYED, B., AYDIN, S., SANUS, G.Z., Cranioplasty: Review of materials and techniques, J Neurosci Rural Pract., 2(2), 2011, 162-167.

2. WOHLERS, T., CAFFREY, T., Wohlers report 2015: 3D printing and additive manufacturing state of the industry annual worldwide progress report, Wohlers Associates, 2015, 1-314.

3. LI, A., AZAD, T.D., VEERAVAGU, A., BHATTI, I., LONG, C., RATLIFF, J.K., LI, G., Cranioplasty Complications and Costs: A National Population-Level Analysis Using the MarketScan Longitudinal Database, World Neurosurgery, 102, 2017, 209 - 220.

4. MRAD, M.A., MURRAD, K., ANTONYSHYN, O., Analyzing the Cost of Autogenous Cranioplasty Versus Custom-Made Patient-Specific Alloplastic Cranioplasty, J Craniofac Surg., 28(5), 2017, $1260-1263$.

5. ZANATY, M., CHALOUHI, N., STARKE, R.M., CLARK, S.W., BOVENZI, C.D., SAIGH, M., SCHWARTZ, E., KUNKEL, E.S., EFTHIMIADIS-BUDIKE, A.S., JABBOUR, P., DALYAI, R., ROSENWASSER, R.H., TJOUMAKARIS, S.I., Complications following cranioplasty: incidence and predictors in 348 cases, J Neurosurg., 123(1), 2015, $182-188$. 
6. MUKHERJEE, S., THAKUR, B., HAQ, I., HETTIGE, S., MARTIN, A.J., Complications of titanium cranioplasty-a retrospective analysis of 174 patients, Acta Neurochir, 156(5), 2014, 989 998.

7. LIANG, E.S., TIPPER, G., HUNT, L., GAN, P.Y.C., Cranioplasty outcomes and associated complications: A single-centre observational study, British Journal of Neurosurgery, 30(1), 2016, 122 $-127$.

8. BRIMIOULLE, S., MORAINE J.J., NORRENBERG, D., KAHN, R.J., Effects of positioning and exercise on intracranial pressure in a neurosurgical intensive care unit, Physical Therapy, 77(12), 1997, 1682-1689.

9. STEINER, L.A., ANDREWS, P.J.D., Monitoring the injured brain: ICP and CBF, British Journal of Anaesthesia, 97(1), 2006, 26-38.

10. DOICIN, C.V., ULMEANU, M.E., SEMENESCU, A., ANTONIAC, V.I., COSTOIU, M.C., MITRICA M., MURZAC R., CHIRTEŞ A., DAVIȚOIU D.V., DOICIN I.E., MATES I.M., 2019, Patent application No. RO133476 (A2).

11. ANTONIAC, V.I., MOHAN, A.G., SEMENESCU, A., DOICIN, C.V., ULMEANU, M.E., COSTOIU, M.C., CAVAlU, S., MURZAC, R., DOICIN, I.E., SĂCELEANU, V., MATEŞ, I.M., 2019, Patent No. RO 132417 (B1).

12. TILLEY, A.R., The Measure of Man and Woman: Human Factors in Design, New York, John Wiley \& Sons Inc., 2002, 1-12.

13. BRAUER R.L., Safety and Health for Engineers, New Jersey, John Wiley \& Sons Inc., 2006, 142143.

14.***Material Data Sheet, Ti6Al4V Titanium Alloy, Arcam EBM System, Available online: http:// www.arcam.com/wp-content/uploads/Arcam-Ti6Al4V-Titanium-Alloy.pdf (accessed on 28.11.2018)

15. ZHANG, J., JUNG, Y.G., 2018, Additive Manufacturing: Materials, Processes, Quantifications and Applications, Butterworth-Heinemann, 2018, 1-362.

16. SUNGAIL, C., ABID, A., Spherical tantalum feed powder for metal additive manufacturing, Metal Powder Report, 73(6), 2018, 316-318.

17. JAKSON, B., LPW Technology enters tantalum powder processing partnership for additive manufacturing, Available online: https://3dprintingindustry.com/news/lpw-technology-enterstantalumpowder-processing-partnership-additive-manufacturing-131151/, (accessed on 18.12.2018)

18. RADOSTINA, V.P., Introduction to Static Analysis Using SolidWorks Simulation, CRC Press, $2017,1-353$.

19. MILNER, R., Cranial Capacity, Chapter in The Encyclopedia of Evolution: Humanity's Search for Its Origins, Holt, New York, 1990, 98.

20. PERSSON, J. HELGASON, B., ENGQVIST, H., FERGUSON, S., PERSSON, C., Stiffness and strength of cranioplastic implant systems in comparison to cranial bone, Journal of CranioMaxillofacial Surgery, 46(3), 2018, 418-423.

Manuscript received: 29.01 .2019 